\title{
On the Necessity of Fictional Deception
}

\author{
Yan-hui WANG \\ Foreign Languages Teaching and Research Dept. ,Luoyang Normal University, \\ Luoyang, China \\ 4456745@163.com
}

Keywords: Fiction, Necessity, Deception, Evolution, Cognition .

\begin{abstract}
As we go back further into our ancestral past, we find that narrative served an even deeper purpose than pleasure. The ability to construct factually accurate narratives allows human beings to process a staggering amount of information during the course of a single lifetime and to transmit their acquired knowledge to their descendants in the form of stories. Fictional narratives can be just as useful in the evolutionary sense because the "blind watchmaker" of natural selection neither knows nor cares what is true. At the deepest level of human cognition, where our values and perceptions have been conditioned by natural selection for millions of generations, it is this utility of fiction - more even than truth or beauty - that must structure and support our universal attraction to literature.
\end{abstract}

\section{Introduction}

The pleasure of fiction, like all forms of pleasure, has been built into the human mind over millions of years - during which those who felt this pleasure did a little bit better in the survival-and-reproduction game than those who did not. For less than a hundred of these years, the pleasure of fiction has been delivered through movies and television shows, before that it came primarily through books, stories, tall tales, folklore, and myth. But as we go back further into our ancestral past, we find that narrative served an even deeper purpose. As the human mind increased in its processing ability, the ability to form narrative sequences allowed us to process and analyze information much more efficiently than we could have done otherwise. The ability to construct factually accurate narratives allows human beings to process a staggering amount of information during the course of a single lifetime and to transmit their acquired knowledge to their descendants in the form of stories. Fictional narratives can be just as useful in the evolutionary sense because the "blind watchmaker" of natural selection neither knows nor cares what is true. Given a choice between a useful fiction and a useless fact, natural selection will choose the useful fiction every time. At the deepest level of human cognition, where our values and perceptions have been conditioned by natural selection for millions of generations, it is this utility of fiction-more even than truth or beauty - that must structure and support our universal attraction to literature.

\section{Deception as Genetic Incentives}

The genetic incentives for men to cuckold other men are clear and easy to see. But why has natural selection left men so vulnerable to this kind of deception? If the cuckold pays a heavy genetic price for his credulity - and all indications are that he does - why haven't easy-to-spot genetic markers evolved to remove all doubt about paternity? The lack of such markers is counterintuitive; it would seem to be in a male's best interest to 
be able to identify his offspring and withhold resources from other men's children. However, when extra-pair conceptions are common, males have a genetic interest in concealing paternity so that their own children will not be identified by other males who might be raising them. A formula developed by Mark Pagel predicts that a rate of extra-pair conception above 10 percent will prevent genetic markers from ever evolving. Concealed paternity, though, brings its own set of problems-problems for which the optimal solution can be found in yet another kind of useful self-deception. Without a marker to establish genetic relatedness a male cannot be sure that a child belongs to somebody else, but he also cannot be sure that it belongs to him. Therefore, as Paola Bressan points out, "all babies start paying the cost of paternity uncertainty, that is, the reduction in paternal care due to fathers not knowing whether they have truly sired their mate's offspring." To minimize this cost, Bressan argues, women have a strong tendency to reassure men of paternity by frequently "remarking on baby's resemblance to her mate." More surprisingly, however, fathers have a strong tendency to believe these reassurances - even when they are false - because of their overall genetic interest in not marking their offspring for identification by others. "We should then expect," he asserts, that "across cultures, mothers should be inclined to claim that babies look just like their daddies." The resemblance of children to their fathers is, therefore, a useful fiction that mothers have an interest in creating and fathers have an interest in believing. This does not mean that women are dishonest and fathers are dupes. Most children really are the offspring of their putative fathers, and most mothers really do perceive a resemblance between their children and their mates. In reality, however, most children do not look very much like their fathers. Studies have shown that people unrelated to a child tend to identify the biological father correctly only slightly more often than random chance would predict. The tendency of mothers to make, and of fathers to believe, exaggerated claims of resemblance appears to be a cognitive adaptation built around a counterfactual proposition that everybody has a genetic interest in believing.

Henrik Ibsen's masterful play, The Wild Duck, offers a stark example of what can happen when a useful fiction is punctured with an ugly truth. The play centers around Hjalmar Ekdal, a man of modest means who lives a quiet, reasonably happy life with his wife, Gina, who helps him run his photography business, and his daughter, Hedvig, who adores him in every way. Hjalmar's happy life comes crashing down, however, when his childhood friend - the hopeless idealist Gregers Werle - returns to town with a mission: to answer the "demands of the ideal" and set his friend's life upon the solid path of truth. Through conversations with Gregers, Hjalmer learns that his family was horridly abused by Gregers's own father, Haakon Werle, who allowed Hjalmer's father to go to prison for a crime that Haakon committed. Hjalmer also learns that his wife was once the mistress of Haakon Werle, who is actually Hedvig's father. Unable to handle the truth, Hjalmer rejects his wife and daughter and leaves his house. The play ends with Hedvig committing suicide by shooting herself in the chest.

The Wild Duck is often seen as a corrective to the progressive idealism that Ibsen himself had advocated in his earlier play An Enemy of the People. (Ibsen, a true satirist, was an equal opportunity annoyer.) Dr. Relling, one of Hjalmer's boarders, takes it upon himself to sustain people's "life lies" - the overriding fiction that people create for themselves to allow them to keep despair at bay. Relling's view, of course, directly contradicts Greger's view that truth is the only stable foundation for a happy life. Werle suffer from weak eyesight brought on by a congenital disorder. This genetic confirmation of paternity hastens Hjalmar's disastrous decision to abandon his family. While Hedvig's paternity remains in doubt, everybody has an interest in believing the 
fiction. When the doubt is removed, the entire family collapses. This is a rough corollary to what happens genetically when markers of paternity become too obvious: everybody involved - mothers, fathers, and children - suffers a decline in their genetic influence.

There is one final area in which self-deception provides an advantage to the self-deceived: those who believe their own lies are much more effective at lying to others. The human mind is a remarkably effective lie detector. Modern polygraphs are designed to measure the minute physiological changes that accompany intentional deception, such as rapid respiration, elevated heart rate, and increased perspiration. However, most people can detect most liars without the aid of technology. Psychologist David Livingston Smith refers to this as the "Pinocchio problem": Effective deception is not always easy, especially when the perpetrator has to face a skeptical audience that is prepared to penalize dishonesty. Deception makes us anxious because lying can be dangerous business. At best, being exposed may mean that others will keep the liar at arm's length. At worst, it may be lethal. Under this kind of pressure, even the most determined con artist is likely to get the jitters. Consequently, human liars tend to follow the example of Pinocchio and rat on themselves by involuntary, nonverbal signs In addition to his expanding nose, Pinocchio has the problem of an overactive conscience - externalized in the original tale, and ever after, as a talking cricket. Thus Pinocchio, like all of us, is doubly constrained in his attempts to deceive others: first by a telltale physiological response and second by a nagging source of anxiety.

\section{The Function of Deceiving both in Biology and Psychology}

Nature, however, has developed an elegant solution to the Pinocchio problem, which the legendary biologist Robert Trivers has explored in several important papers. "We are selected," Trivers insists, "to deceive ourselves the better to deceive others." Trivers supports his argument about the biological role of self-deception with important findings in cognitive psychology - and, specifically, with a series of experiments by Ruben C. Gur and Harold A. Sackeim. After establishing that people have identifi able physiological responses to hearing their own voices - which can be measured through galvanic skin response (gsr) readings - Gur and Sakheim tested subjects by playing recordings of different people speaking and asked them to identify their own voices. They found that people's unconscious responses to their own voice, as measured by gsr reactions, were substantially more accurate than their reported responses. This was true of those who misidentified their own voice as that of someone else as well as for those who misidentified other voices as their own. From this evidence the researchers theorized that people have four cognitive prerequisites for selfdeception: 1) we can believe contradictory things; 2) we can hold these contradictory beliefs simultaneously in different regions of the brain; 3 ) we tend to be consciously aware of only one of the contradictory beliefs; and 4) in our conscious minds we tend to hold false beliefs about ourselves in relation to others. What do we lie to ourselves about in order to successfully lie to others?

Almost any lie could be a candidate if we manage to convince ourselves that we are telling the truth. Think of the Manchurian Candidate scenario in which an American soldier during the Korean War, hypnotized by Chinese agents to become an assassin, is activated by posthypnotic commands and kills without ever realizing what he is doing. If self-deception does occur in such dramatic cases, it does so too infrequently for natural selection to pay much attention. But self-deceptive fictions need not be drastic 
to be useful; Trivers and others have identified a number of more plausible scenarios where internal delusions may operate quite effectively to support external deceptions.

We have seen how Don Quixote's delusions of grandeur help him in a conflict with a younger and stronger man, demonstrating Richard Wrangham's "performanceenhancement hypothesis." Quixote, however, does not actually deceive Carrasaco, as Wrangham's second hypothesis - the "opponent-deception hypothesis"-might predict; this is largely because Carrasco already knows Quixote well enough to avoid the deception. Usually we must assess the strength of a potential opponent immediately before deciding between fight and flight. As Wrangham states, "in conflicts involving mutual assessment, an exaggerated assessment of the probability of winning increases the probability of winning. Selection therefore favors this form of overconfidence." The tendency to overestimate one's own competence in relation to others appears nearly universal among human beings. Researchers refer to this as the "Lake Wobegone Effect," referring to Garrison Keillor's radio description of a town "where all the women are strong, all the men are good looking, and all the children are above average." In his 1991 book, How We Know What Isn't So, Thomas Gilovich explores some of the statistical evidence that confirms the existence of this general bias of self-deception. Trivers points out that, by "deceiving down," an organism can "make itself appear less large, less threatening, and perhaps less attractive, thereby gaining an advantage." In human relations, people who underestimate their own abilities - and successfully convince others to do the same-realize the considerable benefit of low expectations. When underestimation does lead to success, it is often judged more impressive than it really is - as when a political candidate considered inarticulate performs with minimal competence in a debate. An even more important benefit of low expectations may be a decrease in requests to expend resources. We seldom do anything for a single reason, but, when we represent our motivations to others - and to ourselves - we invariably put them in the best light possible, emphasizing the altruistic reasons for our actions and deemphasizing those that are selfi sh, spiteful, or just plain silly. We can usually make this case quite successfully because it does not involve the overt fabrication of a motive, but rather an exclusive focus on one part of a mixed motive combined with a partial suppression of another. However, as Trivers points out, even when we deceive our conscious selves about our motivations, "it must be advantageous for the truth to be registered somewhere, so that mechanisms of self-deception are expected to reside side-by-side with mechanisms for the correct apprehension of reality."

\section{Conclusion}

Closely related to self-deception about motives is self-deception about future intentions. All of us, I suspect, have promised to do something with the full conscious intention of keeping the promise, even though we realize, at some level, that we will probably never follow through. At the moment that we make such a promise, we fully perceive ourselves as telling the truth. Once we obtain whatever present benefits come from the promise of future service, we become much less committed to our promise than we were when we were making it. Many candidates for public office, I'm sure, really do believe the promises they make during an election, and many young couples absolutely mean the things that they promise each other before they are married. Without such promises people would never get married or elected to office; however, they are broken so frequently that few people really expect them to be kept. Memories We deceive 
ourselves about the present when we conceal our motives, and about the future when we misstate our intentions. But the most active area of self-deception is almost certainly our memory of the past. This natural sketchiness of memory gives us nearly endless opportunities to deceive ourselves about things that happened in the past so that we can more convincingly deceive others. All of the data on human deception and self-deception makes it tempting to conclude that evolution made human beings exceptionally good liars.

\section{References}

[1] For a brief introduction to the "modular mind theory" see Pinker, How the Mind Works, 27-31. For a more complete treatment see Spolsky, Gaps in Nature, 19-39.

[2] Kerzel, "Representational Momentum," 180. See also Levine and Klin, "Tracking of Spatial Information"; Rinck et al., "Spatial Situation Models"; Morrow, Greenspan, and Bower, "Accessibility and Situation Models."

[3] Pinker, How the Mind Works, 355. 